\title{
Associations between perceived social and physical environmental variables and physical activity and screen time among adolescents in four European countries
}

\author{
J. Bucksch, J. Kopcakova, J. Inchley, P.J. Troped, G. Sudeck, D. Sigmundova, H. Nalecz, \\ A. Borraccino, F. Salonna, Z. Dankulincova Veselska, Z. Hamrik
}

\begin{tabular}{|l|l|}
\hline Date of deposit & 16112018 \\
\hline Document version & Author's accepted manuscript \\
\hline Access rights & $\begin{array}{l}\text { C 2018, Swiss School of Public Health (SSPH+). This work is } \\
\text { made available online in accordance with the publisher's policies. } \\
\text { This is the author created, accepted version manuscript following } \\
\text { peer review and may differ slightly from the final published } \\
\text { version. }\end{array}$ \\
\hline $\begin{array}{l}\text { Citation for } \\
\text { published version }\end{array}$ & $\begin{array}{l}\text { Bucksch, J., Kopcakova, J., Inchley, J., et al. (2018). } \\
\text { Associations between perceived social and physical environmental } \\
\text { variables and physical activity and screen time among } \\
\text { adolescents in four European countries. International Journal of } \\
\text { Public Health, First Online. }\end{array}$ \\
\hline $\begin{array}{l}\text { Link to published } \\
\text { version }\end{array}$ & \begin{tabular}{l} 
https://doi.org/10.1007/s00038-018-1172-9 \\
\hline
\end{tabular}
\end{tabular}

Full metadata for this item is available in St Andrews Research

Repository at: https://research-repository.st-andrews.ac.uk/

\section{St Andrews Research Repository}




\section{Abstract}

\section{Objectives}

3 Associations between the perceived social and physical environment and self-

4 reported moderate-to-vigorous physical activity (MVPA) and screen time (ST) were 5 examined among adolescents in four European countries.

\section{Methods}

7 Representative samples were surveyed with standardised methodologies.

8 Associations between environmental variables and meeting MVPA recommendations

9 and tertiles of ST were tested in gender-specific logistic regression models.

Moderation by country and country-specific relationships were also examined.

\section{Results}

The most consistent findings across countries were found for the significant associations between neighbourhood social environment and MVPA in both boys and girls. Significant associations with the physical environment varied more between countries and by gender. The most consistent negative associations with ST were with found for the social environmental variable of having parental rules for spending time outside the home.

\section{Conclusions}

The present findings provided evidence for the generalisability of the associations between environmental correlates and MVPA across four European countries. The findings show clear differences in correlates for MVPA and ST. Further research is needed to better understand the unique aspects of the social and physical environment which explain each of the two behaviours. 


\section{Introduction}

Moderate-to-vigorous intensity physical activity (MVPA) is positively associated with better health in youth (Poitras et al. 2016), but MVPA levels are low in most developed countries. For example, recent data from 32 mainly European countries suggest that only $23 \%$ of boys and $14 \%$ of girls meet the current guideline of at least 60 minutes MVPA per day. (Kalman et al. 2015). Furthermore, evidence indicates that sedentary behaviour - especially screen time (ST) - is linked to various adverse health-related outcomes. These associations are largely independent of MVPA levels (Carson et al. 2016). Although the prevalence of ST in industrialised countries is already high (Verloigne et al. 2016), marked increases in ST among youth from 2002 to 2010 have recently been reported with an increase of 2.16 hours per weekday in 15-year-old boys and of 2.11 in 15-years-old girls (Bucksch et al. 2016).

Social ecological models emphasise that lifestyle behaviours, such as physical activity, are influenced by wider societal and environmental factors as well as individual level factors (Sallis et al. 2008). However, evidence on environmental correlates of MVPA and ST among youth are inconsistent (Chastin et al. 2016; Ding et al. 2011; Stierlin et al. 2015). With regard to ST in particular, most studies to date have focused on demographic and behavioural variables (Chastin et al. 2016; Stierlin et al. 2015). Findings indicate social and physical environmental variables, such as having rules for restricting TV use (Bjelland et al. 2015) or a physical activity friendly neighborhood, are associated with lower ST (Veitch et al. 2011). In terms of MVPA, physical environmental features, such as neighborhood walkability and access or proximity to recreation facilities have the most robust associations (Ding et al. 2011). In addition the social environment seems to play an important role for youth MVPA and ST by providing social networks and social support for healthy behaviors 
(Macdonald-Wallis et al. 2012; Sawka et al. 2013; Stierlin et al. 2015). Furthermore several studies have shown that the physical activity of friends is connected to higher MVPA and lower screen time (Garcia et al. 2017; Sirard et al. 2013).

Interestingly most evidence on social and physical environmental correlates of MVPA and ST is from individual countries outside of Europe (Ding et al. 2011; Ferreira et al. 2007; Stierlin et al. 2015) or from pooled cross-national data (Kopcakova et al. 2017). Therefore more generalisable findings from cross-national studies sharing the same methodological approach are limited (Ding et al. 2013; Kerr et al. 2013). Especially in youth, cross-national data are scarce. Recently, The International Study of Childhood Obesity, Lifestyle and the Environment examined correlates of total sedentary time and ST across 12 countries and did not find significant associations with neighborhood environmental variables, but spending more time outside was significantly correlated with reduced overall sitting and ST (Leblanc et al. 2015).

Therefore, the purpose of this study was to examine the associations between perceived social and physical environment and MVPA as well as ST among adolescents in four European countries participating in the Health Behaviour in School-aged Children (HBSC) study: Czech Republic, Germany, Poland and Slovakia.

\section{Methods}

The HBSC study is a World Health Organization collaborative cross-national study conducted in countries across Europe and North America. All participating countries have to use a a standardised mandatory questionnaire assessing a broad range of self-reported health behaviours and health outcomes, as well as social contextual 
factors. In addition, countries may include additional items (optional packages) to provide more in-depth knowledge about certain topics (e.g. active travel, physical activity motivation, snacking behaviour). To ensure cross-national comparability, the mandatory and optional items are standardised and have been back-translated in each language of participating countries. Data are collected every four years from a nationally representative random cluster sample of 11-, 13- and 15-year-old adolescents within each participating country. The primary sampling units are schools and classes. This paper presents data from the 2014 survey conducted in the Czech Republic, Germany, Poland and Slovakia on MVPA and ST (TV viewing, computer use for gaming and non-gaming purposes) as well as an optional package about physical activity-related perceptions of social and physical environment (Currie et al. 2014).

\section{Sample}

A total of 18,781 (Czech Republic: $n=5082$ [52.4\% girls], Germany: $n=5961$ [49.0\% girls], Poland: $n=4545$ [50.2\% girls], Slovakia: $n=3193$ [50.5\% girls]) students were recruited. Surveys were administered by the class teachers or trained interviewers, participation was voluntary, with anonymity and confidentiality of the participants ensured. Response rates were $89.2 \%$ in Czech Republic, $72.5 \%$ in Germany, 86.1\% in Poland and $78.8 \%$ in Slovakia.

\section{Survey items}

\section{Moderate-to-vigorous intensity physical activity}


MVPA was assessed by asking: "On how many days in the past week were you physically active for 60 minutes or more". MVPA was defined as "any activity that increases your heart rate and makes you get out of breath some of the time" with examples of such activities. Response categories were: "0 days" to "7 days". The original version of this MVPA question asked one item about physically active days in a typical week and one item about the last seven days and has moderate validity when assessed against accelerometry data $(.40 \leq r \leq .49)$ (Prochaska et al. 2001; Ridgers et al. 2012). In our study we used only the item about last seven days as both items are highly correlated (Currie et al. 2014). This item has an acceptable testretest reliability (.60 $\leq$ ICC $\leq$.82) (Bobakova et al. 2015; Liu et al. 2010; Prochaska et al. 2001).

MVPA was dichotomised as meeting current guidelines (Janssen and Leblanc 2010) for adolescents responding that they were active for at least 60 minutes on each of the last seven days and not meeting guidelines was $<60$ minutes per day over the last seven days.

\section{Screen time}

ST was assessed by asking about TV viewing and computer use during leisure time for gaming and non-gaming purposes on weekdays. These items previously showed acceptable test-retest reliability $(.57 \leq \mathrm{ICC} \leq .80)$ across three countries (Bobakova et al. 2015).

TV viewing during leisure time was assessed by asking "About how many hours a day do you usually watch television (including DVDs and videos) in your free time?" . Computer use for gaming purposes was measured by asking "How many hours a day, in your free time, do you usually spend playing games on a computer, games 
console, tablet (like iPad), smartphone or other electronic device (not including moving or fitness games)?". A second item for computer use was phrased "How many hours a day, in your free time, do you usually spend using electronic devices such computers, tablets (like iPad) or smart phones for other purposes, for example, homework, emailing, tweeting, facebook, chatting, surfing the internet?" and represents the non-gaming part of computer use. As not all countries asked about weekend days, we only use the data for the question about weekdays. Response options ranged from "none at all" to more than 7 hours/day for all three questions. Responses were recoded as a continuous variable as follows: "none at all" = 0 , "about half an hour a day" = 0.5 , "about 1 hour a day" = 1 , "about 2 hours a day" = 2 etc. and "about 7 or more hours a day" $=7.5$. To represent overall ST, we summed up the hours per day reported for each of the three ST behaviours. Since the distribution of overall ST was skewed, we computed tertiles for the whole sample to analyse low ( $<3.5$ hours per school day), middle ( 3.5 to 7 hours per school day) and high (>7 hours per school day) ST.

\section{Perceived social and physical environment}

Seven items measuring aspects of the perceived social and physical environment were included as independent variables. These were phrased as follows: "It is safe to walk or play alone in my neighbourhood during the day"; "There are other children nearby home to go out and play with."; "There is somewhere at home I can go out and play."; "There are playgrounds or parks close to my home where I can play."; "At school there are playgrounds or fields where I can run around."; "I always have to tell my parents where I am when I go out." and "If I am going out I always have to be back by a certain time." For each item, a 3-item response scale was used (definite 
agreement, definite disagreement or undecided). According to the list above the items cover four distinct domains - safety [1 item], social with respect to home and neighbourhood [2], built environment [2] and social with respect to parental rules [2] and were previously cross-nationally validated in terms of factorial and construct validity (Ommundsen et al. 2008). For the purposes of the current analysis, associations were examined for each item separately since each one represents a unique and discrete aspect of the social and physical environment. Accordingly, social and physical environmental variables were dichotomised by collapsing disagreement and undecided responses (referent) compared to agreement. As we are using variables about the perceived environment, we decided that only an agreement can be interpreted as a positive perception that should be compared with undecided/disagreement.

\section{Covariates}

We controlled for age and family affluence in analyses. Since the sampling was based on three specific age groups, age was treated as a three-stage categorical variable. The family affluence scale (FAS) provides a measure of household material affluence among adolescents and has previously been shown to be valid. Four items were included in the FAS: number of computers, car ownership, family holidays in the past year, and having one's own bedroom (Boyce et al. 2006). Responses were summed to a composite score and treated as a continuous variable ranging from 0-7, with higher scores representing higher family affluence.

\section{Data analysis}


Analyses were conducted with SPSS v21, using the complex samples module to account for the clustered study design with "school class" as the primary sampling unit. Descriptive data for gender, MVPA, ST, each social and physical environmental variable, age group and FAS are presented as numbers and percentages overall and for each country. Logistic regression was used to examine the association between each social and physical environmental variable and meeting recommendations for MVPA. In addition, multinomial logistic regression was used to examine the association between each environmental variable and tertiles of ST. Odds ratios are calculated with high levels of ST as the reference category. For both outcomes we tested whether associations with the social and physical environment varied by country by including interaction terms into each model. If the interaction was significant, we present only country specific results. In the case of non-significant interactions, we also present an overall odds ratio for all 4 countries combined. We display the odds ratios and $95-\%$ confidence intervals for country with forest plots. All models adjusted for age and family affluence. Results are presented separately for boys and girls, since prevalence of MVPA/ST and their correlates differs by gender (Atkin et al. 2014; Stierlin et al. 2015). The level of significance was set at 0.05.

\section{Results}

Table 1 presents the overall and country-specific characteristics of participants. The prevalence of meeting the MVPA recommendation ranged from $15.6 \%$ in Germany to $32.9 \%$ in Slovakia. Across the four countries, the proportion of youth classified as engaging in a high level of ST ranged from $26.4 \%$ in Slovakia to $37.8 \%$ in Germany. Aspects of the social and physical environment were generally perceived positively with the lowest agreement for parental rules. 
In Figure 1, the association between each social and physical environmental variable and meeting MVPA guidelines is shown with forest plots, stratified by gender. While associations varied across countries and between boys and girls within countries, the direction of effects was similar. Furthermore no significant interaction between country and environmental correlates was observed. Within the total sample, significant positive associations with meeting MVPA recommendation were found for the two neighborhood-related social environmental variables (i.e. other children nearby or at home to play with) as well as with having playgrounds and parks near home in boys $(\mathrm{OR}=1.24 ; 95 \%-\mathrm{Cl}: 1.10-1.40)$ and girls $(\mathrm{OR}=1.17 ; 95 \%-\mathrm{Cl}: 1.03-1.34)$. Having school yards to run around was only associated with meeting the MVPA recommendation among girls $(\mathrm{OR}=1.22 ; 95 \%-\mathrm{Cl}$ : 1.06-1.41). No significant association was found for safety of walking and parental rules (i.e. tell parents when I go out and being back at a certain time).

In Figures 2 and 3, the findings are presented for ST in boys and girls, respectively. Since all interactions between country and environmental correlates with ST in each gender group were statistically significant, only country specific results are shown. Odds ratios greater than 1 indicate less ST.

Across countries the most consistent significant associations with low and medium ST were found for the two parental rules variables. Associations between ST and other environmental variables, showed different patterns by country and gender.

Taken gender and countric more specifically into account, we observed except for girls in Germany and boys in Slovakia non-significant associations for one item of the parental rules the item (i.e. being back home by a certain time). Furthermore, having someone at home to play with as well as having places at school to play and run around showed significant associations in German girls and in case of having 
someone at home also in Czech girls. In boys, both social items are related with ST in Germany, where those having other children to play with were significantly more likely to report low or medium ST. Concerning the perceived neighborhood safety we found an association with lower levels of ST among German girls. In boys this association was observed in all countries except Poland.

\section{Discussion}

The most consistent findings across four European countries were found for the associations between neighbourhood-related social environment and MVPA in both boys and girls. Some significant associations with the physical environment were also observed in the whole sample but varied more between countries. Additionally, our study gives more insights into the connection between the social and physical environment and ST. In contrast with MVPA, the most consistent associations with lower ST were with social aspects of having rules for going outside and coming back at a certain time, indicating that correlates might be behaviour specific. Other associations varied more widely between countries and might therefore be more dependent on social and cultural conditions within each country.

\section{Physical activity}

The consistent findings on neighbourhood related social environmental correlates and MVPA in our study highlights the importance of having others at home or nearby for children to play with and be active. Other studies confirm this finding (Ferreira et al. 2007; Ommundsen et al. 2006). Interpersonal relationships are one important dimension of the social environment that are able to shape and promote MVPA in youth through social support or social networks (Macdonald-Wallis et al. 2012; 
Sawka et al. 2013). In contrast, young people's perception of how safe it is to walk or play alone in their neighbourhood was unrelated to MVPA in our study. A recent review also reported equivocal findings for safety issues (Ding et al. 2011). In addition, it has been shown that the perceptions of safety concerns among parents are more important predictors of physical activity in their children than the children's perceptions (Carver et al. 2008).

We also found that perceived physical environment features such as having parks or playgrounds close to home or having schools with playgrounds or fields where youth can play and be physically active near home were positively related to MVPA in the overall sample. Another European study using the same two built environment measures also observed a small but significant positive relationship with PA (Ommundsen et al. 2006). Systematic reviews found that access to parks and playgrounds was positively associated with physical activity in about half of the studies (Davison and Lawson 2006; Ding et al. 2011). In sum, it is difficult to draw firm conclusions across studies as both physical activity and neighbourhood environmental characteristics are measured in different ways (subjectively or objectively) and studies focus on different domains and types of physical activity.

Some gender differences are also apparent in our findings. For example, we observed that having school grounds where fields and places for running around are available may be more supportive for MVPA in girls than in boys. Some studies also suggest that girls may benefit more than boys from activity-friendly environments (Davison and Lawson 2006; Patnode et al. 2010). The reasons for such gender differences are likely to be varied. Similar to participation in organised sports, boys are generally more likely to take part in unstructured physical activity and free play compared to girls (Badura et al. 2015; Patnode et al. 2010) and spend more time in 
independent and unsupervised mobility (Schoeppe et al. 2014; Stone et al. 2014).

This appears to indicate that boys find ways of being active outside without the need

271 for supervised physical activity and areas where specific physical activities are

272 structured or guided.

273 While our findings reveal significant associations between the social and physical environment and MVPA in the overall sample, we also observed differences in the magnitude of associations across countries. However, the direction of the associations in most cases were not different. Therefore it could be argued that the pooled effect size (i.e., odds ratio) has a higher power and including data from different countries provides a larger variability in environmental features to determine the true effect size (Kerr et al. 2013). However, the overall effect size is an average estimate that prevents from observing between-country differences which might be important to decide about at a national level (Ding et al. 2013). Comparing countries, it seems that for example in Czech Republic and Poland parks and playgrounds are unrelated to MVPA.

\section{Screen time}

The findings for ST reveal a more complex picture that is different from MVPA correlates. First, the variability in the associations with the social and physical environment across countries indicated by significant interactions prevented us from calculating overall odds ratios. The most consistent finding was in relation to social environment with respect to parental rules. If girls and boys have to tell their parents where they are when they go out and play, they are more likely to report lower ST. Our items on parental rules do not relate specifically to ST. However, it could be hypothesised in more general terms that families who have rules about daily life activities like going out, might also use rules to restrict ST which, in turn, have been 
shown to reduce ST behaviour (Bjelland et al. 2015). Higher levels of parental monitoring may be applicable across a number of different aspects of a young person's life. Comparably, one study has shown that restricting outdoor play increases ST (Atkin et al. 2013). This association warrants further investigation.

Our data also suggest that having other children to go out and play with is not important for ST,. As there is clear evidence that ST and MVPA are largely independent behaviours, children and adolescents can be both physically active and also find time to use screens for a high amount of time (Pearson et al. 2014). Accordingly, having friends to go out and play with may not result in fewer opportunities for ST; indeed it is possible that these same friends also engage in ST together.

Our findings also reveal an association between perceiving the neighbourhood as safe for walking during daytime and reduced ST in three countries for boys. In contrast, perceiving the neighbourhood as safe was unrelated to MVPA in our findings. It might be that those adolescents who feel their neighbourhood is unsafe are less likely to spend time outdoors and consequently more likely to engage in ST. A recent international study has shown that spending a lot of time outside is one of the most consistent predictors of reduced ST in youth (Leblanc et al. 2015). Similarly, greater independent mobility is related to reduced ST (Stone et al. 2014). In addition, other studies have shown that greater independent mobility among young people is associated with higher perceived safety (Schoeppe et al. 2015; Veitch et al. 2006). This highlights the importance of creating safe places where young people are allowed to spent time outdoors. Among girls, a significant association between neighbourhood safety and ST was only observed in Germany, suggesting that safety issues are less important for girls. As highlighted before, a number of studies 
emphasise that boys are more likely to be allowed to spend time unsupervised outdoors and therefore safety issues may be more relevant for boys than girls, or boys may be more aware of safety concerns within their neighbourhood. This finding also underlines the need to address parental safety concerns so that girls are allowed to play outside more and be more independently mobile.

Physical environment was mainly unrelated with ST in our study. Existing reviews confirm the inconsistent association between physical neighbourhood environment and ST, with the exception of living in urban areas which was related to higher ST (Pate et al. 2011; Uijtdewilligen et al. 2011). However, understanding the (environmental) correlates of sedentary behaviours such as ST is in its infancy and more studies are needed to identify the most important correlates (Stierlin et al. 2015).

\section{Strengths and limitations}

The main strengths of this study are the comparisons across four European countries with large representative samples of youth and using a common methodological approach that is essential for providing a more robust evidence base. However, some limitations have to be considered when interpreting our findings. First, we present cross-sectional data so that we are not able to infer causality. Second, we used selfreports to assess MVPA, ST, and the social and physical environment. While most items have been shown to have acceptable validity and reliability, self-reports are prone to misclassification leading to biased effects. With respect to ST it has been shown that at least TV viewing is overestimated compared to a diary by 1 hour per day in boys and 20 minutes per day in girls (Vereecken et al. 2006). However, self- 
reports of ST are limited in terms of quantifying valid estimates (Atkin et al. 2012). Therefore we decided to use tertiles to rank adolescents as low, medium and high users of ST. This approach seems to be acceptable as it attenuates bias.

Furthermore, we only used weekday patterns of ST as not in all countries data for weekend day. While ST patterns differ between weekdays and weekend days (Bucksch et al. 2012) our findings are limited only to weekdays. Third, since we focused on perceived social and physical environmental correlates, it is possible that active adolescents are more aware of these features and may therefore be more likely to report about them. Lastly, we only adjusted for individual variables and may therefore have missed potential country-level confounders such as economic factors, social norms or climate.

\section{Conclusion}

Our study is among the first to present European cross-national data on the associations between the social and physical environment and both MVPA and ST in youth with a standardised methodological approach. The findings provided evidence for the generalisability of the associations between the social and physical environment and PA. The findings show clear differences in correlates of MVPA and ST. Further research is therefore needed to better understand the unique aspects of the social and physical environment which could explain each of the two behaviours, independently. Future studies should also use objectively georeferenced features of the environment in addition to perceived measures to gain more insights into the relationships with MVPA and ST. Future studies will also increase explanatory power by using objective measures to capture MVPA and ST levels. More international studies with a broader variety of countries are needed to confirm the generalisability 
368 of findings found herein. It is clear that in accordance with a socio-ecological

369 approach both the social and physical environment are associated with young

370 people`s physical activity and sedentary behaviour. Therefore interventions to

371 promote physical activity and reduce sedentary behaviour must target multiple

372 societal levels and should also take gender differences into account.

\section{Competing interests/ethical standards}

374 The authors declare that they have no competing interests and study was in 375 compliance with ethical standards. 


\section{References}

Atkin AJ, Gorely T, Clemes SA, Yates T, Edwardson C, Brage S, Salmon J, Marshall SJ, Biddle SJ (2012) Methods of measurement in epidemiology: sedentary behaviour. Int J Epidemiol 41:1460-1471. doi: 10.1093/ije/dys118

Atkin AJ, Corder K, Ekelund U, Wijndaele K, Griffin SJ, van Sluijs, Esther M F (2013) Determinants of change in children's sedentary time. PLoS ONE 8:e67627. doi: 10.1371/journal.pone.0067627

Atkin AJ, Sharp SJ, Corder K, van Sluijs, Esther M F (2014) Prevalence and correlates of screen time in youth: an international perspective. Am J Prev Med 47:803-807. doi:

10.1016/j.amepre.2014.07.043

Badura P, Geckova AM, Sigmundova D, van Dijk JP, Reijneveld SA (2015) When children play, they feel better: organized activity participation and health in adolescents. BMC Public Health 15:1090. doi: 10.1186/s12889-015-2427-5

Bjelland M, Soenens B, Bere E, Kovács É, Lien N, Maes L, Manios Y, Moschonis G, Te Velde, Saskia J (2015) Associations between parental rules, style of communication and children's screen time. BMC Public Health 15:1002. doi: 10.1186/s12889-015-2337-6

Bobakova D, Hamrik Z, Badura P, Sigmundova D, Nalecz H, Kalman M (2015) Test-retest reliability of selected physical activity and sedentary behaviour HBSC items in the Czech Republic, Slovakia and Poland. Int J Public Health 60:59-67. doi: 10.1007/s00038-014-0628-9

Boyce W, Torsheim T, Currie C, Zambon A (2006) The Family Affluence Scale as a Measure of National Wealth: Validation of an Adolescent Self-Report Measure. Soc Indic Res 78:473-487. doi: 10.1007/s11205-005-1607-6

Bucksch J, Sigmundova D, Hamrik Z, Troped PJ, Melkevik O, Ahluwalia N, Borraccino A, Tynjälä J, Kalman M, Inchley J (2016) International trends in adolescent screen-time behaviors from 2002 to 2010. J Adolesc Health 58:417-425. doi: 10.1016/j.jadohealth.2015.11.014

Carson V, Hunter S, Kuzik N, Gray CE, Poitras VJ, Chaput J-P, Saunders TJ, Katzmarzyk PT, Okely AD, Connor Gorber S, Kho ME, Sampson M, Lee H, Tremblay MS (2016) Systematic review of sedentary behaviour and health indicators in school-aged children and youth: an update. Appl Physiol Nutr Metab 41:65. doi: 10.1139/apnm-2015-0630

Carver A, Timperio A, Crawford D (2008) Playing it safe: the influence of neighbourhood safety on children's physical activity. A review. Health \& Place 14:217-227. doi:

10.1016/j.healthplace.2007.06.004

Chastin SFM, Craemer M de, Lien N, Bernaards C, Buck C, Oppert J-M, Nazare J-A, Lakerveld J, O'Donoghue G, Holdsworth M, Owen N, Brug J, Cardon G (2016) The SOS-framework (Systems of Sedentary behaviours): an international transdisciplinary consensus framework for the study of determinants, research priorities and policy on sedentary behaviour across the life course: a DEDIPAC-study. Int J Behav Nutr Phys Act 13:83. doi: 10.1186/s12966-016-0409-3

Currie C, Inchley J, Molcho M, Lenzi M, Veselska Z, Wild F (2014) Health Behavour in School-aged Children (HBSC) Study Protocol: Background, Methodology and Mandatory items for the 2013/14 Survey. CAHRU, St. Andrews

Davison KK, Lawson CT (2006) Do attributes in the physical environment influence children's physical activity?: A review of the literature. Int J Behav Nutr Phys Act 3:19

Ding D, Sallis JF, Kerr J, Lee S, Rosenberg DE (2011) Neighborhood environment and physical activity among youth a review. Am J Prev Med 41:442-455. doi: 10.1016/j.amepre.2011.06.036 
Ding D, Adams MA, Sallis JF, Norman GJ, Hovell MF, Chambers CD, Hofstetter CR, Bowles HR, Hagstromer M, Craig CL, Gomez LF, Bourdeaudhuij I de, Macfarlane DJ, Ainsworth BE, Bergman P, Bull FC, Carr H, Klasson-Heggebo L, Inoue S, Murase N, Matsudo S, Matsudo V, McLean G, Sjostrom M, Tomten H, Lefevre J, Volbekiene V, Bauman AE (2013) Perceived neighborhood environment and physical activity in 11 countries: do associations differ by country? Int J Behav Nutr Phys Act 10:57. doi: 10.1186/1479-5868-10-57

Ferreira I, van der Horst K, Wendel-Vos W, Kremers S, van Lenthe FJ, Brug J (2007) Environmental correlates of physical activity in youth - a review and update. Obes Rev 8:129-154. doi: 10.1111/j.1467-789X.2006.00264.x

Garcia JM, Agaronov A, Sirard JR, Whaley D, Rice DJ, Weltman A (2017) Psychosocial and Friend Influences on Objective Sedentary Behavior and Screen Time: A Mixed Methods Analysis. J Phys Act Health 14:213-221. doi: 10.1123/jpah.2016-0035

Janssen I, Leblanc AG (2010) Systematic review of the health benefits of physical activity and fitness in school-aged children and youth. Int J Behav Nutr Phys Act 7:40. doi: 10.1186/1479-5868-7-40

Kalman M, Inchley J, Sigmundova D, lannotti RJ, Tynjala J, Hamrik Z, Haug E, Bucksch J (2015) Secular trends in moderate-to-vigorous physical activity in 32 countries from 2002 to 2010: a crossnational perspective. Eur J Public Health 25:S37-S40

Kerr J, Sallis JF, Owen N, Bourdeaudhuij I de, Cerin E, Sugiyama T, Reis R, Sarmiento O, Fromel K, Mitas J, Troelsen J, Christiansen LB, Macfarlane D, Salvo D, Schofield G, Badland H, Guillen-Grima F, Aguinaga-Ontoso I, Davey R, Bauman A, Saelens B, Riddoch C, Ainsworth B, Pratt M, Schmidt T, Frank L, Adams M, Conway T, Cain K, van Dyck D, Bracy N (2013) Advancing science and policy through a coordinated international study of physical activity and built environments: IPEN adult methods. J Phys Act Health 10:581-601

Kopcakova J, Dankulincova Vaselska Z, Madarasova Geckova A, Bucksch J, Nalecz H, Sigmundova D, van Dijk JP, Reijneveld SA (2017) Is a perceived activity-friendly environment associated with more physical activity and fewer screen-based activities in adolescents? Int J Environ Res Public Health 14:39

Leblanc AG, Katzmarzyk PT, Barreira TV, Broyles ST, Chaput J-P, Church TS, Fogelholm M, Harrington DM, Hu G, Kuriyan R, Kurpad A, Lambert EV, Maher C, Maia J, Matsudo V, Olds T, Onywera V, Sarmiento OL, Standage M, Tudor-Locke C, Zhao P, Tremblay MS (2015) Correlates of Total Sedentary Time and Screen Time in 9-11 Year-Old Children around the World: The International Study of Childhood Obesity, Lifestyle and the Environment. PLoS ONE 10:e0129622. doi: 10.1371/journal.pone.0129622

Liu Y, Wang M, Tynjala J, Lv Y, Villberg J, Zhang ZY, Kannas L (2010) Test-retest reliability of selected items of Health Behaviour in School-aged Children (HBSC) survey questionnaire in Beijing, China. BMC Med Res Methodol 10. doi: 10.1186/1471-2288-10-73

Macdonald-Wallis K, Jago R, Sterne JA (2012) Social network analysis of childhood and youth physical activity: A systematic review. Am J Prev Med 43:636-642. doi: 10.1016/j.amepre.2012.08.021

Ommundsen Y, Klasson-Heggebo L, Anderssen SA (2006) Psycho-social and environmental correlates of location-specific physical activity among 9- and 15- year-old Norwegian boys and girls: The European Youth Heart Study. Int J Behav Nutr Phys Act 3:32

Ommundsen Y, Page A, Ku PW, Cooper AR (2008) Cross-cultural, age and gender validation of a computerised questionnaire measuring personal, social and environmental associations with children's physical activity: the European Youth Heart Study. Int J Behav Nutr Phys Act 5:29. doi: 10.1186/1479-5868-5-29 
Pate RR, Mitchell JA, Byun W, Dowda M (2011) Sedentary behaviour in youth. Br J Sports Med 45:906-913. doi: 10.1136/bjsports-2011-090192

Patnode CD, Lytle LA, Erickson DJ, Sirard JR, Barr-Anderson D, Story M (2010) The relative influence of demographic, individual, social, and environmental factors on physical activity among boys and girls. Int J Behav Nutr Phys Act 7:79. doi: 10.1186/1479-5868-7-79

Pearson N, Braithwaite RE, Biddle SJH, van Sluijs EMF, Atkin AJ (2014) Associations between sedentary behaviour and physical activity in children and adolescents: a meta-analysis. Obes Rev 15:666-675. doi: 10.1111/obr.12188

Poitras VJ, Gray CE, Borghese MM, Carson V, Chaput J-P, Janssen I, Katzmarzyk PT, Pate RR, Connor Gorber S, Kho ME, Sampson M, Tremblay MS (2016) Systematic review of the relationships between objectively measured physical activity and health indicators in school-aged children and youth. Appl Physiol Nutr Metab 41:239. doi: 10.1139/apnm-2015-0663

Prochaska JJ, Sallis JF, Long B (2001) A physical activity screening measure for use with adolescents in primary care. Arch Pediatr Adolesc Med 155:554-559

Ridgers ND, Timperio A, Crawford D, Salmon J (2012) Validity of a brief self-report instrument for assessing compliance with physical activity guidelines amongst adolescents. J Sci Med Sport 15:136-141. doi: 10.1016/j.jsams.2011.09.003

Sallis J, Owen N, Fisher EB (2008) Ecological models of health behavior. In: Glanz K, Rimer BK, Viswanath K (eds) Health behavior and health Education, vol 4. Jossey-Bass, San Francisco, pp 465-485

Sawka K, McCormack GR, Nettel-Aguirre A, Hawe P, Doyle-Baker PK (2013) Friendship networks and physical activity and sedentary behavior among youth: a systematized review. Int J Behav Nutr Phys Act 10:130. doi: 10.1186/1479-5868-10-130

Schoeppe S, Duncan MJ, Badland HM, Oliver M, Browne M (2014) Associations between children's independent mobility and physical activity. BMC Public Health 14:91. doi: 10.1186/1471-245814-91

Schoeppe S, Duncan MJ, Badland HM, Alley S, Williams S, Rebar AL, Vandelanotte C (2015) Sociodemographic factors and neighbourhood social cohesion influence adults' willingness to grant children greater independent mobility: A cross-sectional study. BMC Public Health 15:690. doi: 10.1186/s12889-015-2053-2

Sirard JR, Bruening M, Wall MM, Eisenberg ME, Kim SK, Neumark-Sztainer D (2013) Physical activity and screen time in adolescents and their friends. Am J Prev Med 44:48-55. doi: 10.1016/j.amepre.2012.09.054

Stierlin AS, Lepeleere S de, Cardon G, Dargent-Molina P, Hoffmann B, Murphy MH, Kennedy A, O'Donoghue G, Chastin SF, Craemer M de (2015) A systematic review of determinants of sedentary behaviour in youth: a DEDIPAC-study. Int J Behav Nutr Phys Act 12:133. doi: 10.1186/s12966-015-0291-4

Stone MR, Faulkner GEJ, Mitra R, Buliung RN (2014) The freedom to explore: examining the influence of independent mobility on weekday, weekend and after-school physical activity behaviour in children living in urban and inner-suburban neighbourhoods of varying socioeconomic status. Int J Behav Nutr Phys Act 11:5. doi: 10.1186/1479-5868-11-5

Uijtdewilligen L, Nauta J, Singh AS, van Mechelen W, Twisk JW, van der Horst K, Chinapaw MJ (2011) Determinants of physical activity and sedentary behaviour in young people: A review and quality synthesis of prospective studies. Br J Sports Med 45:896-905. doi: 10.1136/bjsports-2011090197 
Veitch J, Bagley S, Ball K, Salmon J (2006) Where do children usually play? A qualitative study of parents' perceptions of influences on children's active free-play. Health \& Place 12:383-393. doi: 10.1016/j.healthplace.2005.02.009

Veitch J, Timperio A, Crawford D, Abbott G, Giles-Corti B, Salmon J (2011) Is the neighbourhood environment associated with sedentary behaviour outside of school hours among children? Ann Behav Med 41:333-341. doi: 10.1007/s12160-011-9260-6

Vereecken CA, Todd J, Roberts C, Mulvihill C, Maes L (2006) Television viewing behaviour and associations with food habits in different countries. Public Health Nutr 9:244-250

Verloigne M, Loyen A, van Hecke L, Lakerveld J, Hendriksen I, Bourdheaudhuij I de, Deforche B, Donnelly A, Ekelund U, Brug J, van der Ploeg, Hidde P (2016) Variation in population levels of sedentary time in European children and adolescents according to cross-European studies: a systematic literature review within DEDIPAC. Int J Behav Nutr Phys Act 13:69. doi:

10.1186/s12966-016-0395-5 